\title{
Facile synthesis of two-photon absorbing polymers through radical copolymerization
}

\author{
X. $B i^{1 *}, Z . W u^{1}, Z . X u^{2}$ \\ ${ }^{1}$ Department of Chemistry, University of Missouri-Kansas City, Kansas City, Missouri 64110, USA \\ ${ }^{2}$ Department of Chemistry and Biochemistry, University of Missouri-St. Louis, St. Louis, Missouri 63121, USA
}

Received 9 April 2007; accepted in revised form 6 June 2007

\begin{abstract}
A two-photon absorbing polymer has been prepared through radical copolymerization of methyl acrylate and a synthesized monomer containing a two-photon absorbing chromophore $(E, E, E)$-1,3,5-tristyrylbenzene (1), under conventional radical polymerization conditions. The synthesized polymer was characterized by nuclear magnetic resonance (NMR), infra-red spectroscopy (IR) and gel permeation chromatography (GPC). The linear and nonlinear optical properties were studied by measurement of UV-Vis absorption, fluorescent emission and two-photon cross-section. This synthetic strategy provided a facile approach for synthesis of photonic materials with adjustable chromophore concentration and high molecular weights.
\end{abstract}

Keywords: polymer synthesis, molecular engineering, two-photon absorbing polymer, radical copolymerization

\section{Introduction}

For the last decade, synthesis of highly active organic two-photon absorbing materials has attracted much interest because of their importance in science and their potential applications in many fast-growing technological areas such as optical power limiting [1, 2], three-dimensional (3-D) storage media [3, 4], two-photon fluorescence microscopy [5, 6], up-conversion lasing [7, 8], and two-photon photodynamic therapy $[9,10]$. The fulfillment of above technological applications relies greatly on the development of organic materials with superior two-photon absorption (TPA) activities. Since 1990s, intensive studies have been conducted and great progress has been made on the discovery of structure-activity relationship in TPA molecules [11-19]. Earlier studies have focused on linear quadrupolar molecular structures, and found that the conjugation length, $\pi$-electron center, and chemical functional groups at the end of electron conjugation are three important factors for the enhancement of TPA activities [11, 15, 16]. Recent studies have demonstrated superior TPA properties of octupolar multi-branched structures in comparison to linear structures $[12,13,20]$. Despite the advances in molecular structure development, most TPA molecules need to be incorporated into polymers to form thin films for many practical applications [21]. In most cases, the TPA molecules are doped in a host polymer matrix [21-23]. The disadvantage of this approach is that TPA molecules may aggregate and undergo phase separation under intense laser irradiation, which leads to the decreasing performance of the material. Moreover, the solubility of chromophores in the polymer is limited, and maximization of chromophore density is difficult. Some TPA conjugated polymers have been reported [24, 25], but synthetic strategies for high molecular-weight TPA materials are still lacking. In this research, we explore the strategy to covalently attach the TPA molecules to the polymethyl

*Corresponding author, e-mail: xiangdongb@yahoo.com

(C) BME-PT and GTE 
acrylate backbone through radical copolymerization of methyl acrylate and a TPA molecule-containing monomer. This approach has practical values in many respects as the TPA molecules in the synthesized materials are stable and phase separation is avoided, and therefore, a consistent behavior of the materials is maintained. Secondly, desired chromophore density can be achieved, high molecular weight polymers can be synthesized, and conventional polymerization procedures can be used. Further more, with the tolerance of radical polymerization to various functionalities, various TPA polymers bearing functional groups can be synthesized and further modified for different applications.

The model of branched two-photon absorbing chromophore employed in this research is $(E, E, E)$ 1,3,5-tristyrylbenzene (1) which has previously been synthesized and was found to exhibit excellent nonlinear optical properties [26-28]. To covalently attach the molecular structure of $\mathbf{1}$ to polymer backbone, a synthetic strategy is developed as depicted in Figure 1. A monomer containing chromophore $\mathbf{6}$ is first synthesized and is copolymerized with methyl acrylate under radical polymerization conditions. The resulting polymer product is extensively characterized and its linear and non-linear optical properties are studied using multiple analytical methods.

\section{Experimental}

\subsection{Materials and instruments}

All chemicals were purchased from Aldrich Chemical Company or Acros Chemical Company and used without further purification. Solvents such as dimethylformamide (DMF) or dimethyl sufoxide (DMSO) were treated with dry molecular sieves and distilled under vacuum. Tetrahedrofuran (THF) was treated with either Na-benzophenone or calcium hydride, and distilled under nitrogen before use. All reactions were conducted under nitrogen. Heck reactions were performed in a Schlenk Tube equipped with a Teflon valve. ${ }^{1} \mathrm{H}$ NMR spectra were measured by a Bruker AM $250(250 \mathrm{MHz})$ spectrometer. ${ }^{13} \mathrm{C}$ NMR spectra were recorded at $62.9 \mathrm{MHz}$ on a Bruker AM $250(250 \mathrm{MHz})$ spectrometer. All samples were referenced to the deuterated solvents. IR spectra were recorded on a Spectrum 2000 (Perkin Elmer) FT-IR spectrometer. TPA cross-sections $( \pm 15 \%$ uncertainty) of synthesized molecules were determined by nonlinear optical transmission measurement [29] using a Quanta-Ray MOPO-730 laser. Molecular weights were determined using gel permeation chromatography (GPC) equipped with a Waters 410-differential refractometer. A flow rate of $1.0 \mathrm{ml} / \mathrm{min}$ was used and samples were prepared in THF. Polystyrene standards were used for calibration.<smiles>C=Cc1cc(/C=C/c2ccccc2)cc(/C=C/c2ccccc2/C=C/c2ccccc2)c1</smiles>

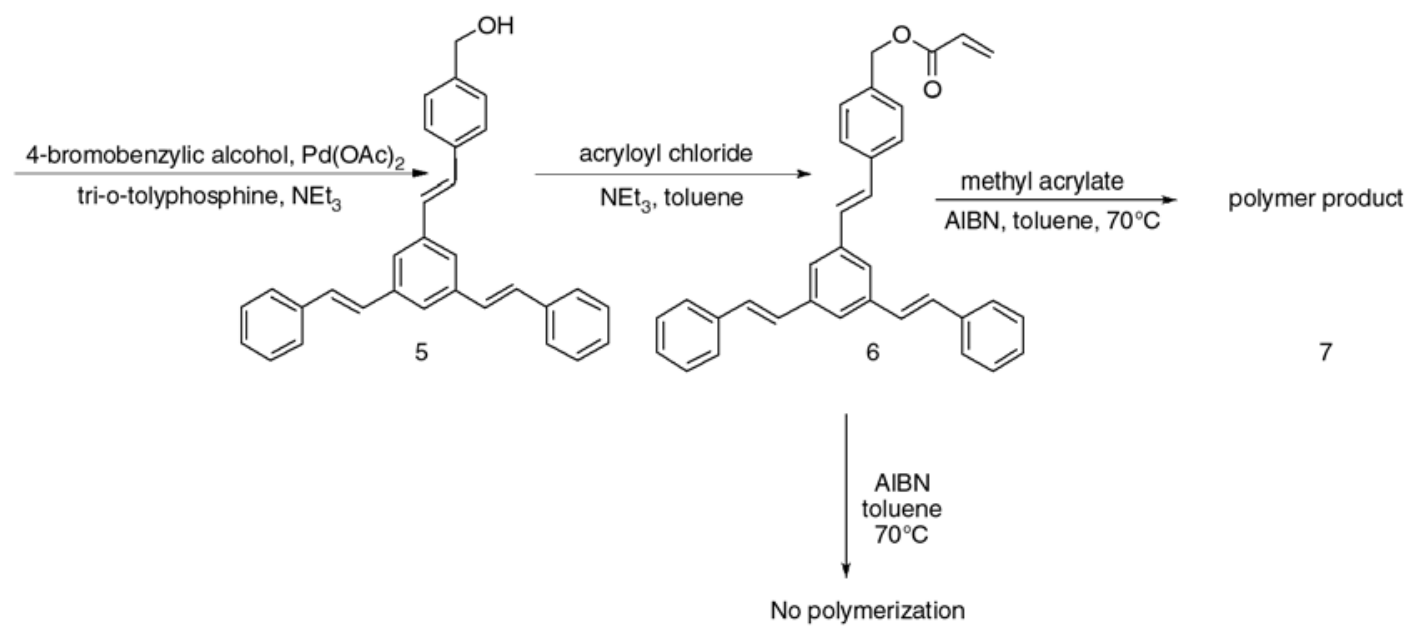

Figure 1. Synthesis of two-photon absorbing polymer through radical copolymerization 


\subsection{Synthesis}

\section{Preparation of (E,E,E)-1,3,5-tristyrylbenzene (1)}

1,3,5-tristyrylbenzene was prepared by Heck reaction of 1,3,5-tribromobenzene and styrene following a reported procedure [28] in $51 \%$ yield. ${ }^{1} \mathrm{H} \mathrm{NMR}\left(\mathrm{CDCl}_{3}, 250 \mathrm{MHz}\right) \delta 7.20-7.59(24 \mathrm{H}, \mathrm{m}$, $\mathrm{ArH}$ and $\mathrm{Ar}-\mathrm{CH}=\mathrm{CH}-\mathrm{Ar}) .{ }^{13} \mathrm{C} \mathrm{NMR}\left(\mathrm{CDCl}_{3}\right.$, $62.9 \mathrm{MHz}) \delta 138.27,137.44,129.52,128.99$, $128.59,128.03,126.82$, and 124.18 .

\section{Preparation of 2}

To a $500 \mathrm{ml}$ round-bottom flask was charged with 1,3,5-tribromobenzene (10 g, $31.1 \mathrm{mmol})$ and ether $(250 \mathrm{ml})$ under nitrogen. The solution was cooled to $-78^{\circ} \mathrm{C}$. Butyl lithium solution $(2.5 \mathrm{M}, 12.4 \mathrm{ml}$, $31.1 \mathrm{mmol}$ ) was injected via a syringe. The reaction mixture was kept at this temperature for $45 \mathrm{~min}$ utes. DMF (2.65 ml, $34.2 \mathrm{mmol}$ ) was added dropwise through a syringe. The solution was allowed to warm to room temperature and stirred for 6 hours. The reaction was quenched with dilute hydrochloric acid and extracted with ether. The organic layer was separated and dried over magnesium sulfate. Solvent was evaporated and crystallization of the residue in ethanol gave product (3.36 g, yield 41\%). ${ }^{1} \mathrm{H} \mathrm{NMR}\left(\mathrm{CDCl}_{3}\right): \delta 9.90(1 \mathrm{H}$, s, CHO), 7.93 (2 H, s, ArH) and 7.91 (1 H, s, ArH). ${ }^{13} \mathrm{C} \mathrm{NMR}\left(\mathrm{CDCl}_{3}\right): \delta 189.4,139.8,132.1,131.4$ and 124.2.

\section{Preparation of $\mathbf{3}$}

To a Schlenk tube equipped with a Teflon valve was weighed $2(0.545 \mathrm{~g}, 2.06 \mathrm{mmol})$, styrene (0.614 ml, $5.37 \mathrm{mmol}), \quad \mathrm{Pd}(\mathrm{OAc})_{2} \quad$ (46.3 mg, $0.206 \mathrm{mmol})$, tri-o-tolylphosphine $(125.6 \mathrm{mg}$, $0.41 \mathrm{mmol})$, triethylamine $(5 \mathrm{ml}, 14.8 \mathrm{mmol})$ and DMF $(5 \mathrm{ml})$. Bubble nitrogen to the solution, seal the tube and put in oil bath at $95^{\circ} \mathrm{C}$ for 3 days. The reaction mixture was poured into water, extracted with ethyl acetate. The organic layer was dried over magnesium sulfate. Purification of the crude product by column chromatography (silica gel, hexanes/ethyl acetate 10:1) gave pure product $(0.409 \mathrm{~g}$, 64\%). ${ }^{1} \mathrm{H}$ NMR $\left(\mathrm{CDCl}_{3}\right): \delta 10.09(1 \mathrm{H}, \mathrm{s}, \mathrm{CHO})$ and 7.92-7.14 (17 H, m, ArH and $\mathrm{Ar}-\mathrm{CH}=\mathrm{CH}-\mathrm{Ar})$. ${ }^{13} \mathrm{C} \mathrm{NMR}\left(\mathrm{CDCl}_{3}\right): \delta 192.5,138.9,137.4,136.9$, $130.9,130.5,129.0,128.4,127.2,127.0$ and 126.5.

\section{Preparation of 4}

To a $25 \mathrm{ml}$ round-bottom flask was added $\mathrm{NaH}$ $(27.8 \mathrm{mg}, 1.1 \mathrm{mmol})$ and dry DMSO $(2 \mathrm{ml})$. The solution was warmed up to $75-80^{\circ} \mathrm{C}$ for 45 minutes then cooled to $0^{\circ} \mathrm{C}$. A solution of $\mathrm{CH}_{3} \mathrm{PPh}_{3} \mathrm{I}$ (444 mg, $1.1 \mathrm{mmol}$ ) in DMSO was injected dropwise. The suspension was stirred at room temperature for 10 minutes. A solution of $\mathbf{3}(310 \mathrm{mg}$, $1 \mathrm{mmol})$ in DMSO was added by a syringe. The reaction was kept at $70^{\circ} \mathrm{C}$ overnight. The mixture was poured into water, extracted with ethyl acetate, dried over magnesium sulfate, and further purified by column chromatography on silica gel to yield the desired product $(1.05 \mathrm{~g}, 95 \%) .{ }^{1} \mathrm{H}$ NMR $\left(\mathrm{CDCl}_{3}\right): \quad \delta 7.61-7.12 \quad(17 \mathrm{H}, \quad \mathrm{ArH}$ and $\mathrm{Ar}-\mathrm{CH}=\mathrm{CH}-\mathrm{Ar}), 6.83\left(\mathrm{H}, \mathrm{m}, \mathrm{Ar}-\mathrm{CH}=\mathrm{CH}_{2}\right), 5.91$ $\left(1 \mathrm{H}, \quad \mathrm{d}, \quad \mathrm{Ar}-\mathrm{CH}=\mathrm{CH}_{2}\right)$ and $5.38(1 \mathrm{H}, \mathrm{d}$, $\left.\mathrm{Ar}-\mathrm{CH}=\mathrm{CH}_{2}\right) .{ }^{13} \mathrm{C} \mathrm{NMR}\left(\mathrm{CDCl}_{3}\right): \delta 138.5,138.1$, 137.4, 136.8, 129.4, 128.9, 128.5, 128.0, 126.8, 124.3, 123.9 and 114.7.

\section{Preparation of 5}

Compound 5 was synthesized by Heck reaction of 4 with 4-bromobenzylic alcohol following a similar procedure as for the preparation of $\mathbf{3}$ (yield 37\%). ${ }^{1} \mathrm{H}$ NMR $\left(\mathrm{CDCl}_{3}\right): \delta 7.58-7.19(23 \mathrm{H}, \mathrm{m}, \mathrm{ArH}$ and $\mathrm{Ar}-\mathrm{CH}=\mathrm{CH}-\mathrm{Ar}), 4.73$ (2 H, s, benzylic) and 2.06 $(1 \mathrm{H}, \mathrm{s}, b r, \mathrm{OH}) .{ }^{13} \mathrm{C} \mathrm{NMR}\left(\mathrm{CDCl}_{3}\right): \delta 140.6$, 138.3, 138.2, 137.4, 136.9, 129.5, 129.0, 128.6, $128.5,128.0,127.7,127.1,127.0,126.8,124.2$ and 65.4 .

\section{Preparation of 6}

To a $25 \mathrm{ml}$ round-bottom flask was charged with toluene ( $2 \mathrm{ml})$, acryl chloride $(64.7 \mathrm{mg}, 0.72 \mathrm{mmol})$ and triethylamine (71 $\mu \mathrm{l}, 0.72 \mathrm{mmol})$. The solution was stirred at room temperature for 10 minutes. A solution of $5(98.7 \mathrm{mg}, 0.24 \mathrm{mmol})$ in toluene $(1 \mathrm{ml})$ was added. The mixture was purified by column chromatography on silica gel to give product 6 (65.1 mg, 58\%). ${ }^{1} \mathrm{H}$ NMR $\left(\mathrm{CDCl}_{3}\right): \delta 7.59-7.20$ $(23 \mathrm{H}, \mathrm{m}, \mathrm{ArH}$ and $\mathrm{Ar}-\mathrm{CH}=\mathrm{CH}-\mathrm{Ar}), 6.50(1 \mathrm{H}, \mathrm{d}$, $\left.-\mathrm{OC}(\mathrm{O}) \mathrm{CH}=\mathrm{CH}_{2}\right), 6.20\left(1 \mathrm{H}, \mathrm{m},-\mathrm{OC}(\mathrm{O}) \mathrm{CH}=\mathrm{CH}_{2}\right)$, $5.89\left(1 \mathrm{H}, \mathrm{d},-\mathrm{OC}(\mathrm{O}) \mathrm{CH}=\mathrm{CH}_{2}\right)$ and $5.23(2 \mathrm{H}, \mathrm{s}$, benzylic). ${ }^{13} \mathrm{C} \mathrm{NMR}\left(\mathrm{CDCl}_{3}\right): \delta 184.1,138.3$, 138.1, 137.6, 137.4, 135.5, 131.5, 129.6, 129.3, $129.0,128.5,128.0,127.1,127.0,126.8,126.7$, 124.2 and 66.3 . 


\section{Polymer synthesis}

To a Schlenk tube was added 6 (51 mg, $0.109 \mathrm{mmol})$, methyl acrylate (49 $\mu \mathrm{l}, 0.54 \mathrm{mmol})$, 2,2'-azobisisobutyronitrile (AIBN, $5.4 \mathrm{mg}$, $0.033 \mathrm{mmol})$ and toluene $(0.3 \mathrm{ml})$. The tube was degassed, sealed, and heated to $70^{\circ} \mathrm{C}$ overnight. Polymer 7 was precipitated in methanol $(60 \mathrm{mg}$, $61 \%$ ) and purified by dissolve-precipitate methods to removed small molecules and dried under vacuum. ${ }^{1} \mathrm{H} \mathrm{NMR}\left(\mathrm{CDCl}_{3}\right): \delta$ 7.73-7.35 (m, br, ArH and $\mathrm{Ar}-\mathrm{CH}=\mathrm{CH}-\mathrm{Ar}$ ), 5.32 ( $\mathrm{br}$, benzylic), 3.65 (br, -COOMe), 2.38 (br, -CH-COOMe), 1.94-1.50 (m, br, $\left.-\mathrm{CH}_{2}-\mathrm{CH}(\mathrm{COOMe})\right)$; FT-IR (KBr) $v_{\max } / \mathrm{cm}^{-1} 3030(\mathrm{C}-\mathrm{H}), 2954(\mathrm{C}-\mathrm{H}), 1739(\mathrm{C}=\mathrm{O})$, 1601 (C=C), $1452\left(-\mathrm{CH}_{2}-\right), 1384,1265,1170$ (C-O), 967 (C-H, aromatic), 831, $754\left(-\mathrm{CH}_{2}-\right)$ and 697 (C-H, aromatic).

\section{Results and discussion}

The synthesis of TPA chromophore-containing monomer (6) started with tribromobenzene (Figure 1), which reacted with DMF to give 3,5-dibromobenzaldehyde (2), according to a reported procedure [30]. A Heck reaction of 2 with 2 equivalents of styrene resulted in compound $\mathbf{3}$, followed by a Wittig reaction with $\mathrm{CH}_{3} \mathrm{PPh}_{3} \mathrm{I}$ to afford the olefin 4, with a procedure described by Greenwald [31]. Further reaction of $\mathbf{4}$ with 4-bromobenzylalcohol under Heck reaction conditions yielded the chromophore 5, in which the TPA chromophore molecule (1) was constructed with an active hydroxyl group at the end for further organic transformations. Esterification of $\mathbf{5}$ with acryloyl chloride gave the chromophore-containing monomer $\mathbf{6}$ for further polymerization. Attempt of the self-

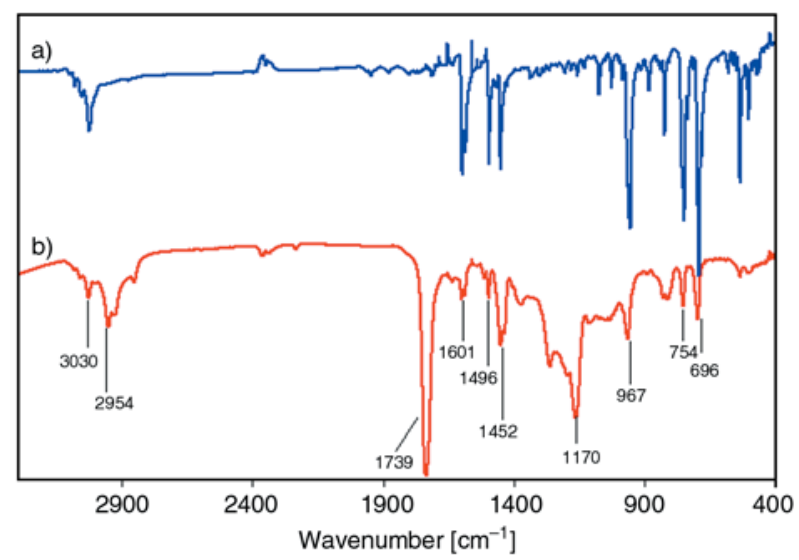

Figure 2. FT-IR of (E,E,E)-1,3,5-tristyrylbenzene (a) and synthesized two-photon absorbing polymer (b) polymerization of $\mathbf{6}$ was not successful, which might be due to steric hindrance of the bulky chromophore structure. However, copolymerization of 6 with methyl acrylate yielded a copolymer with the TPA molecules randomly attached to the polymer backbone. The copolymerization was conducted in the presence of AIBN with a loading ratio of methyl acrylate to 6 as 5:1. The molar concentration of the chromophore in the synthesized copolymer is calculated to be $21.7 \%$ based on proton NMR integration.

The polymer product (7) was further characterized by FT-IR (Figure 2b). For comparison, the FT-IR spectrum of compound $\mathbf{1}$ was also displayed (Figure $2 \mathrm{a}$ ). In Figure $2 \mathrm{~b}$, a strong $\mathrm{C}=\mathrm{O}$ stretch at $1739 \mathrm{~cm}^{-1}$ is observed from the carboxylate branches connected to polymethyl acrylate backbone. Other characteristic peaks such as 1170 (C-O stretch), 2954 (C-H stretch), and $1452 \mathrm{~cm}^{-1}$ ( $-\mathrm{CH}_{2}-$ bending) also match the reported absorptions of polymethyl acrylate [32]. By comparison to Figure $2 \mathrm{a}$, the IR absorptions at 3030 (C-H stretch), 1601 and 1496 (C=C stretch), 967 and 696 (aromatic $\mathrm{C}-\mathrm{H})$, and $754 \mathrm{~cm}^{-1}\left(-\mathrm{CH}_{2}-\right.$ bending) can be identified as peaks from the two-photon chromophore that covalently attached to the polymer backbone. The synthesized polymer is readily soluble in THF, methylene chloride, and chloroform. The UV-Vis absorption and fluorescent emission of the synthesized polymer resemble those of molecule 1 (Figure 3) as they both exhibit similar maximum absorption, emission, and profiles. Similar to molecule $\mathbf{1}$, the UV-Vis absorption peak of the polymer occurs at $313 \mathrm{~nm}$ and there is no linear absorption observed above $400 \mathrm{~nm}$. Under inten-

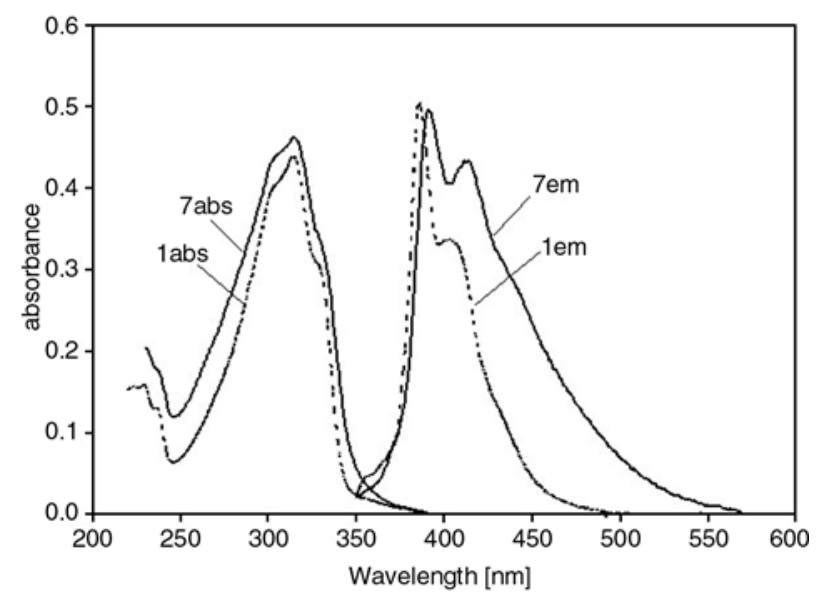

Figure 3. UV-Vis and fluorescence emission spectra of $(E, E, E)-1,3,5$-tristyrylbenzene (1) and the synthesized two-photon absorbing polymer (7) 
sive laser excitation at $532 \mathrm{~nm}$, however, a strong absorption is observed and an up-converted fluorescent emission occurs at $390 \mathrm{~nm}$, which is featured for two two-photon absorption. The TPA cross-sections of molecule $\mathbf{1}$ and the polymer at $532 \mathrm{~nm}$ were determined using transmission twophoton absorption measurement [29]. The TPA cross-section of the synthesized polymer is about $44670 \cdot 10^{-50} \mathrm{~s} \mathrm{~cm}^{4}$ in nanosecond time domain, while that of molecule 1 is about $17700 \cdot 10^{-50} \mathrm{~s} \mathrm{~cm}^{4}$. The higher apparent TPA cross-section of the polymer could be the result of higher local density of TPA chromophores within a polymer chain, since the total two-photon absorption is proportional to the square of number density. Further GPC analysis indicates that the polymer exhibits a fairly high molecular weight $\left(M_{w} 7750, M_{n} 25300\right)$ with the polydispersity index (PDI) of 3.2. A solution of the synthesized polymer in THF is stored for a week and no significant difference is observed on it optical properties, indicating that the polymer product is optically stable. Further stability experiments under laser irradiation and heat are under investigation.

\section{Conclusions}

This research has demonstrated a facile synthesis of a two-photon absorbing polymer through conventional radical polymerization of methyl acrylate and a synthesized monomer containing a two-photon absorbing chromophore. The synthesized polymer shows similar optical properties comparable to the chromophore molecule alone and is optically stable. This method offers a convenient procedure to synthesize high molecular weight two-photon absorbing materials. The concentration of chromophore can be adjusted by varying the ratio of bulk monomer to chromophore-containing monomer, and the physical properties of bulk materials can be tuned for specific application by using different commercial monomers. The advantage of radical polymerization procedure also provides the possibility to synthesize functional two-photon absorbing materials for a verity of applications.

\section{References}

[1] Bhawalkar J. D., He G. S., Prasad P. N.: Nonlinear multiphoton processes in organic and polymeric materials. Reports on Progress in Physics, 59, 1041-1070 (1996).
[2] Ehrlich J. E., Wu X. L., Lee I. Y. S., Hu Z. Y., Röckel H., Marder S. R., Perry J. W.: Two-photon absorption and broadband optical limiting with bis-donor stilbenes. Optics Letters, 22, 1843-1845 (1997).

[3] Cumpston B. H., Ananthavel S. P., Barlow S., Dyer D. L., Ehrlich J. E., Erskine L. L., Heikal A. A., Kuebler S. M., Lee I. Y. S., McCord-Maughon D., Qin J., Röckel H., Rumi M., Wu X. L., Marder S. R., Perry J. W.: Two-photon polymerization initiators for threedimensional optical data storage and microfabrication. Nature, 398, 51-54 (1999).

[4] Parthenopoulos D. A., Rentzepis P. M.: Three-dimensional optical storage memory. Science, 245, 843-845 (1989).

[5] Denk W., Svoboda K.: Photon upmanship: why multiphoton imaging is more than a gimmick. Neuron, 18, 351-357 (1997).

[6] Denk W., Strickler J. H., Webb W. W.: Two-photon laser scanning fluorescence microscopy. Science, $\mathbf{2 4 8}$ 73-76 (1990).

[7] Mukherjee A.: Two-photon pumped upconverted lasing in dye doped polymer waveguides. Applied Physics Letters, 62, 3423-3425 (1993).

[8] Zhao C. F., He G. S., Bhawalkar J. D., Park C. K., Prasad P. N.: Newly synthesized dyes and their polymer/glass composites for one- and two-photon pumped solid-state cavity lasing. Chemistry of Materials, 7, 1979-1983 (1995).

[9] Bhawalkar J. D., Kumar N. D., Zhao C. F., Prasad P. N.: Two-photon photodynamic therapy. Journal of Clinical Laser Medicine and Surgery, 15, 201-204 (1997).

[10] Prasad P. N., Bhawalkar J. D., Kumar N. D., Lal M.: Multifunctional polymers as multi-role materials for photonics. Macromolecular Symposia, 118, 467-472 (1997).

[11] Albota M., Beljonne D., Bredas J. L., Ehrlich J. E., Fu J. Y., Heikal A. A., Hess S. E., Kogej T., Levin M. D., Marder S. R., McCord-Maughon D., Perry J. W., Rockel H., Rumi M., Subramaniam C., Webb W. W., Wu I. L., Xu C.: Design of organic molecules with large two-photon absorption cross sections. Science, 281, 1653-1656 (1998).

[12] Chung S-J., Kim K-S., Lin T-C., He G. S., Swiatkiewicz J., Prasad P. N.: Cooperative enhancement of two-photon absorption in multi-branched structures. The Journal of Physical Chemistry: B, 103, 10741-10745 (1999).

[13] Kannan R., He G. S., Lin T. C., Prasad P. N., Vaia R. A., Tan L. S.: Toward highly active two-photon absorbing liquids. synthesis and characterization of 1,3,5-triazine-based octupolar molecules. Chemistry of Materials, 16, 185-194 (2004).

[14] Kannan R., He G. S., Yuan L. X., Xu F. M., Prasas P. N., Dombroskie A. G., Reinhardt B. A., Baur J. W., Vaia R. A., Tan L. S.: Diphenylaminofluorene-based two-photon-absorbing chromophores with various electron acceptors. Chemistry of Materials, 13, 1896 1904 (2001). 
[15] Kim O. K., Lee K. S., Woo H. Y., Kim K. S., He G. S., Swiatkiewicz J., Prasad P. N.: New class of two-photon-absorbing chromophores based on dithienothiophene. Chemistry of Materials, 12, 284-286 (2000).

[16] Reinhardt B. A., Brott L. L., Clarson S. J., Dillard A. G., Bhatt J. C., Kannan R., Yuan L. X., He G. S., Prasad P. N.: Highly active two-photon dyes: design, synthesis, and characterization toward application. Chemistry of Materials, 10, 1863-1874 (1998).

[17] Rumi M., Ehrlich J. E., Heikal A. A., Perry J. W., Barlow S., Hu Z. Y., McCord-Maughon D., Parker T. C., Röckel H., Thayumanavan S., Marder S. R., Beljonne D., Bredas J. L.: Structure-property relationships for two-photon absorbing chromophores: bis-donor diphenylpolyene and bis(styryl)benzene derivatives. Journal of American Chemical Society, 122, 95009510 (2000).

[18] Varnavski O., Samuel I. D. W., Palsson L. O., Beavington R., Burn P. L., Goodson T.: Investigations of excitation energy transfer and intramolecular interactions in a nitrogen corded distyrylbenzene dendrimer system. The Journal of Chemical Physics, 116, 88938903 (2002).

[19] Yan Y-X., Tao X-T., Sun Y-H., Wang C-K., Xu G-B., Yang J-X., Ren Y., Zhao X., Wu Y-Z., Yu X-Q., Jiang M-H.: Synthesis and nonlinear optical properties of novel multi-branched two-photon polymerization initiators. Journal of Materials Chemistry, 14, 29953000 (2004).

[20] Wei P., Bi X. D., Wu Z., Xu Z.: Synthesis of Triphenylamine-Cored Dendritic Two-Photon Absorbing Chromophores. Orginc Letters, 7, 3199-3202 (2005).

[21] Hua J. L., Li B., Meng F. S., Ding F., Qian S. X., Tian H.: Two-photon absorption properties of hyperbranched conjugated polymers with triphenylamine as the core. Polymer, 45, 7143-7149 (2004).

[22] Guo F. Q., Guo R., Jiang Z. W., Zhang Q. J., Huang W. H., Guo B.: Optical properties of a novel nonlinear chromophore doped polymer and application for twophoton microfabrication. Physica Status Solidi (a), 202, 2515-2520 (2005).
[23] Wang D., Zhou G. Y., Ren Y., Yu X. Q., Cheng X. F., Yang S. J., Xu X. G., Shao Z. S., Jiang M. H.: Linear and nonlinear optical properties of two-photon absorption dye doped linear copolymer. Solid State Communications, 121, 339-344 (2002).

[24] Chung S. J., Maciel G. S., Pudavar H. E., Lin T. C., He G. S., Swiatkiewiez J., Prasad P. N.: Two-photon properties and excitation dynamics of poly(pphenylenevinylene) derivatives carrying phenylanthracene and branched alkoxy pendents. The Journal of Physical Chemistry. A, 106, 7512-7520 (2002).

[25] Hohenau A., Cagran C., Kranzelbinder G., Scherf U., Leising G.: Efficient continuous-wave two-photon absorption in para-phenylene-type polymers. Advanced Materials, 13, 1303-1307 (2001).

[26] Benshafrut R., Rabinovitz M., Dee-Noor-Barzilay Z., Meijere A.: Metal reduction of di- and trisubstituted styrylbenzenes: formation of the highly charged tetraand hexaanions. Journal of Physical Organic Chemistry, 12, 333-339 (1999).

[27] Malkes L. Y., Kovalenko N. P.: Synthesis of triarylsubstituted 1,3,5-trivinylbenzenes. Zhurual Obshchei Khimii, 2, 297-298 (1966).

[28] Meier H., Hanold N., Kalbitz H.: Synthesis of hexastyrylbenzenes. Synthesis, 3, 276-278 (1997).

[29] He G. S., Yuan L. X., Cheng N., Bhawalkar J. D., Prasad P. N., Brott L. L., Clarson S. J., Reinhardt B. A.: Nonlinear optical properties of a new chromophore. Journal of the Optical Society of America B: Optical Physics, 14, 1079-1087 (1997).

[30] Miller T. M., Neenan T. X., Zayas R., Bair H. E.: Synthesis and characterization of a series of monodisperse, 1,3,5-phenylene-based hydrocarbon dendrimers including $\mathrm{C}_{276} \mathrm{H}_{186}$ and their fluorinated analogues. Journal of American Chemical Society, 114, 1018 1025 (1992).

[31] Greenwald R., Chaykovsky M., Corey E. J.: The wittg reaction using methylsulfinyl carbanion-dimethyl sulfoxide. Journal of Organic Chemistry, 28, 1128-1129 (1963).

[32] Alipour M., Massoumi B., Safa K. D., Entezami A. A.: Living radical polymerization of methyl methacrylate, methyl acrylate and their block copolymers with acrylonitrile by atom-transfer radical polymerization. Iranian Polymer Journal, 10, 99-106 (2001). 